\title{
Competência de trabalhadores da construção civil na resolução de problemas práticos: A relação entre representação e prática na ação eficaz
}

Renata Bastos Ferreira Antipoff. Instituto Federal de Minas Gerais.

Cristina de Castro Frade. Universidade Federal de Minas Gerais.

\begin{abstract}
Resumo
Este artigo trata das inter-relações entre representações e prática na ação eficaz, por meio da análise das atividades de pedreiros. Duas posições antagônicas têm dominado o debate, polarizado entre a predominância das representações ou dos aspectos situacionais e corporais na ação competente. Para o cognitivismo, as representações determinam a ação eficaz, já para a ação situada, as habilidades incorporadas e as interações locais explicam a eficácia da ação. Apresentamos uma alternativa que situa a inteligência humana no âmbito da prática, sua dimensão representacional aparecendo como cognição na ação, através de um estudo empírico realizado com dois trabalhadores da construção civil resolvendo problemas no canteiro de obras. A metodologia do Curso da Ação mostra-se adequada a este propósito pois permite analisar a atividade sem cair no cognitivismo. Os resultados confirmam a pertinência de deslocar a inteligência prática para o âmbito da própria prática, confirmando assim o paradigma da ação situada.
\end{abstract}

Palavras-chave: competência; representação; ação situada; construção civil.

\begin{abstract}
Civil construction's workers competence in practical problem solving: The relation between representation and practice in the effective action. This article deals with the interrelations between representations and practice in effective action, through the analysis of masons activities. Two opposite positions have dominated the debate polarized between the representations predominance and situational and physical aspects in the competent action. For cognitivism, representations determine the effective action but for the already located action, the incorporated skills and local interactions explain the action effectiveness. We present an alternative that places human intelligence within the practice, its representational dimension emerging as cognition in the action, through an empirical study of two construction workers solving problems at the construction site. The Course of Action methodology proves to be suitable for this purpose because it allows to analyze the activity without tending into cognitivism. The results confirm the relevance of carrying practical intelligence to the level of the practice itself, thus confirming the paradigm of situated action.
\end{abstract}

Keywords: competence; representation; situated action; construction site. 


\section{Resumen}

Competencia de trabajadores de la construcción civil en la resolución de problemas prácticos: La relación entre representación y práctica en acción eficaz. Este artículo trata sobre las inter-relaciones entre representaciones y la práctica en acción eficaz, por medio del análisis de las actividades de albañiles. Dos posiciones antagónicas han estado dominando el debate, polarizado entre la predominancia de las representaciones o de los aspectos situacionales y corporales en la acción competente. Para el cognitivismo, las representaciones determinan la acción eficaz, ya para la acción situada, las habilidades incorporadas y las interacciones locales explican la eficacia de la acción. Presentamos una alternativa que sitúa la inteligencia humana en el ámbito de la práctica, su dimensión representacional apareciendo como cognición en la acción, a través de un estudio empírico realizado con dos trabajadores de la construcción civil resolviendo problemas en el sítio de construcción. La metodología del Curso de la Acción se muestra adecuada a este propósito pues permite analizar la acción sin caer en el cognitivismo. Los resultados confirman la pertinencia de dislocar la inteligencia práctica para el ámbito de la propia práctica, confirmando así el paradigma de la acción situada.

Palabras clave: competência; representación; acción situada; construcción civil.

As discussões em torno da eficácia da ação têm dividido opiniões acerca dos determinantes da competência, especialmente quando envolve saberes matemáticos, atividade lógico-formal por excelência. A matemática, como ação humana de medir, contar, desenhar, localizar, jogar e explicar relações entre fenômenos (Bishop, 1988), está presente em todas as culturas espaIhadas pelo mundo, embora haja diferenças significativas na forma de desenvolver suas atividades. Essas distintas formas de agir são, em nível mais geral, enquadradas em duas categorias: matemática escolar ou científica, e matemática não escolar ou mundana, desenvolvida na prática. O que as diferencia, essencialmente, é a presença da matemática escolar como ferramenta na resolução de problemas da vida prática ou sua ausência, neste caso compensada pela presença de outras habilidades incorporadas e desenvolvidas no dia a dia do trabalho, como mostram as pesquisas realizadas em temas como Etnomatemática (Duarte, 2002; Knijnik, Wanderer, Giongo, \& Duarte, 2012), Psicologia da Educação Matemática (Acioly-Régnier, 1995; Carraher, Carraher, \& Schliemann, 1988; Da Rocha Falcão,1996), Aprendizagem Situada (Lave, 2011; Lave \& Wenger, 1991), Antropologia (Gatewood, 1985) e Ergonomia (Bisseret, 1995).

Vários pesquisadores e estudiosos têm debatido sobre essas duas matemáticas, relativas a operações do pensamento, com o intuito de explicar ou melhorar o desempenho dos atores sociais. Os defensores da corrente cognitivista, representada por Vera e Simon (1993), atribuem a ação eficaz à presença de representações na mente dos indivíduos, como os saberes matemáticos escolares, os quais, uma vez manipulados no pensamento, determinam a resolução correta dos problemas práticos envolvendo a matemática. De um lado, é o domínio de um cálculo ou de uma operação matemática de tipo escolar (uso de algoritmos, conceitos e instrumentos matemáticos) que permite aos sujeitos agirem competentemente nas situações mundanas que envolvem algum tipo de habilidade matemática, como medir, contar, desenhar, localizar, etc. Por outro lado, a perspectiva da Ação Situada, defendida por autores como Suchman (1987); Lave (2011); Lave e Wenger (1991) e Ingold (2010), é caracterizada pelas habilidades incorporadas como o lócus principal da ação inteligente. Nesse caso, mesmo sem dominar a matemática escolar, o indivíduo pode ser altamente habilidoso e eficaz na resolução de problemas práticos quando são desenvolvidos esquemas corporais (habilidades incorporadas) em situações reais de trabalho, na prática e pela prática, conforme Lave (2011).

Este artigo aborda a ação de trabalhadores da construção civil resolvendo problemas práticos em um canteiro de obras, sob dois aspectos: de um lado, o emprego de representações matemáticas escolares no controle da ação e, de outro, o uso de habilidades incorporadas, desenvolvidas como fator decisivo da eficácia. A pergunta que se coloca é: o indivíduo é mais eficaz quando representações mentais de tipo escolar organizam a ação (abordagem cognitivista) ou quando suas habilidades incorporadas (Ação Situada) são desenvolvidas na prática profissional e mobilizadas em situação real de resolução de problemas? Esta questão remete ao debate entre estudiosos cognitivistas e defensores da ação situada, que atribuem importância distinta ao papel 
dos processos cognitivos (planejamento, manipulação de conceitos explícitos, cálculos, inferências, reflexões) e do corpo (percepção e ação), na gênese da ação eficaz.

Esta problemática será tratada a partir da análise dos dados de uma pesquisa, que teve como principal objetivo o estudo das competências práticas de trabaIhadores da construção civil na resolução de problemas que envolvem a matemática. O material empírico foi analisado à luz do embate fundamental a respeito da gênese da ação eficaz, por meio de três abordagens teóricas: 1) a teoria cognitivista e sua influência nas pesquisas de Psicologia da Educação Matemática, que atribuem à ação eficaz a presença de representações na mente dos sujeitos; 2 ) a perspectiva da Ação Situada e as pesquisas em Antropologia Cognitiva, cujos estudiosos priorizam a análise das práticas sociais e das habilidades incorporadas, considerando-as o ponto fulcral do agir competente; e 3) a teoria do Curso da Ação que fornece subsídios teórico-metodológicos para se compreender a ação em seu evolver, descrevendo aspectos constitutivos (percepção-ação-cognição) no desempenho eficaz (Lima, 1995; Suchman, 1987; Theureau, 2004). Nosso objetivo é demonstrar, empiricamente, qual tese sobre a ação eficaz é mais plausível: aquela que atribui às representações mentais o lócus da competência ou a que defende a supremacia da ação situada, como habilidades incorporadas e emergentes no curso da ação. Os resultados trazem implicações consideráveis para se pensar a formação de trabalhadores e o desenvolvimento de competências práticas em situações profissionais.

\section{O Debate entre representação e ação situada na inteligência prática}

\section{O Cognitivismo}

A Ciência Cognitiva clássica ou Cognitivismo (Vera, 2003; Vera \& Simon, 1993) pressupõe a existência de representações mentais determinando a ação do corpo, isto é, ditando cada passo a ser realizado. O mundo é representado na mente dos indivíduos, constituindo representações mentais (saberes representados) que refletem a realidade. Estas representações determinam a ação dos sujeitos, crucial para a sua eficácia. O plano serve para estabelecer ações e prever as respostas exigidas no mundo real. Sua capacidade preditiva e antecipatória previne o aparecimento de surpresas indesejáveis, que podem por em risco o sucesso da ação. O modelo, mesmo que atualizado em situação, sempre preexiste à ação, e tem de ser assim, sob pena da ação fracassar ou estar à mercê o tempo todo dos imprevistos e das variabilidades (Vera \& Simon, 1993). Assim, quanto mais planejada e elaborada na mente é a ação antes de ser realizada (plano), maior é a chance de ser bem-sucedida.

Ser competente, nessa perspectiva, implica possuir, na mente, representações sobre o mundo que, ao serem manipuladas, determinam a ação. A manipulação prévia de representações matemáticas, como algoritmos, cálculos, conceitos, medidas, é o que nos permite resolver os problemas práticos com eficácia, ao passo que não possuí-las, é estar fadado ao fracasso, ao retrabalho, ao trabalho mal feito, ao desperdício e aos erros. Muitos pesquisadores em Educação Matemática (Carraher et al, 1988; Da Rocha Falcão, 2006) se basearam nessa concepção cognitivista para explicar a ação eficaz na resolução de problemas envolvendo matemática na vida cotidiana. Para estes, a habilidade corporal, como o salto com vara, por exemplo, (Vergnaud, 1996), é resultado de um conjunto bem-planejado de cálculos mentais, inferências e reflexões sobre representações de distância, força, elasticidade, etc. Segundo Vergnaud (1996), "há então um cálculo em pensamento no curso do desenrolar do salto: um esquema comporta inferências" (p. 279). O saltador bem-sucedido calcula e manipula mentalmente as representações operatórias da distância, da força, da elasticidade da vara para saltar, e assim obtém sucesso. A eficácia é determinada pelo conjunto de representações que o sujeito manipula na mente, antes de agir.

\section{A Ação Situada}

Contrária a essa concepção, encontra-se a perspectiva da Ação Situada (Lave, 2011; Suchman, 1987), que recoloca o problema da relação entre prática e representações, não mais numa relação causal ou de supradeterminação, mas numa relação na qual as representações sejam recursos da ação situada. A tese central é de que a ação inteligente depende de habilidades incorporadas e mobilizadas em situação, como a percepção e o gesto. O corpo é o epicentro da ação inteligente, como o é também para a fenomenologia.

A fenomenologia, de acordo com Merleau-Ponty (1945), coloca a primazia da ação inteligente no corpo, nos esquemas sensório-motores, demonstrando que sabemos fazer sem precisar pensar sobre a ação (seguir um plano), ou sem que seja necessário usar representações mentais para agir com eficácia. $O$ exemplo dos jogadores de tênis de Merleau-Ponty (1968) demonstra bem esta habilidade corporal: 
Trata-se do jogo de tênis ou de qualquer outro esporte, é preciso levar em consideração uma quantidade de dados: vento, velocidade da bola, posição do adversário, natureza do campo, momento da partida. O corpo faz prova de inteligência diante das situações inteiramente novas, o gesto resolve um problema que não foi colocado pela inteligência e cujos elementos são infinitamente numerosos (p.266).

Em outras palavras, o corpo sabe! Se esse jogador de tênis habilidoso tivesse de calcular mentalmente o vento, a distância, a velocidade da bola, a posição do adversário, e ainda escolher a melhor estratégia para ser bem-sucedido, com certeza ele perderia o time do jogo, o momento certo, a destreza, a rapidez do gesto. Ele age sem pensar nestas variáveis, deixando seu corpo responder habilmente às solicitações da partida. As representações, nesta perspectiva, ao invés de determinarem a ação por meio de um plano elaborado e seguido mentalmente, estão incorporadas nos gestos e na percepção (Suchman, 2007). Não há uma separação entre pensar e agir, refletir sobre o quê fazer para, em seguida, fazer (como seguir um plano), mas, sim, o pensamento na ação, emergindo no corpo do sujeito engajado na situação aqui e agora, como o faz o navegador no meio da correnteza (Suchman, 2007). Em vez de seguir um plano de ação (conjunto coerente de passos lógicos), ele o abandona e se deixa levar pelas habilidades incorporadas, que vão se manifestando no decorrer do percurso. Esta habilidade incorporada não é produto de princípios explícitos conscientes, como planos e representações guiando os passos do navegador, mas resultado de um saber-fazer incorporado, adquirido na vivência prática de situações reais.

O saber-fazer incorporado consiste em habilidades corporais, como gestos, percepções, sensações e emoções. Já as representações são ferramentas do ator para agir. Suchman (2007) utiliza a analogia do cego com sua bengala, para mostrar essa relação instrumental da representação na ação. Devido à tamanha intimidade e habilidade desenvolvidas no uso da bengala para sentir o mundo, o cego não mais a sente, ele sente o mundo. O mesmo ocorre com as representações: o sujeito vê o mundo com as representações, são meios para ver e agir, sem que para isso seja preciso refletir sobre elas, calculá-las, seguir um plano de passos lógicos e coerentes, para agir com eficácia.

Essa perspectiva da Ação Situada influenciou muitos pesquisadores do campo da Antropologia, interessados em compreender e descrever a ação humana inteligente (Gatewood, 1985; Ingold, 2010; Lave, 2011), sem, no entanto, oferecer um método adequado para a análise e descrição das habilidades incorporadas em situação. A primazia do corpo (habilidades incorporadas) na ação eficaz e a imbricada relação entre representação e ação, a primeira como artefato invisível infiltrado na ação, vão encontrar respaldo na proposta teórico-metodológica apresentada no Curso da Ação (Theureau, 1992; 2004), que contribui para a análise das habilidades incorporadas sem cair na descrição cognitivista.

\section{O Curso da Ação}

A abordagem teórico-metodológica apresentada pela perspectiva do Curso da Ação (Theureau, 2004), desenvolvida no âmbito da ergonomia francofônica, parte da hipótese da ação situada ancorada no paradigma da enação (Varela, Thompson, \& Rosch, 1991), segundo a qual a ação emerge em situação impregnada de saber. $\mathrm{O}$ ator social olha, percebe, sente e faz, de acordo com o que é significativo para ele a cada instante do curso da ação, sem que este conhecimento seja representado na mente, mas incorporado e emergente em situação. Por isso, para Theureau (2004), "os fenômenos cognitivos pertinentes referem-se essencialmente à percepção e à ação" (p.14). A consciência presente no curso da ação é pré-reflexiva, isto é, o saber incorporado nos gestos e na percepção não é consciente para o sujeito que o realiza, não resulta, pelo menos durante a ação, de manipulações na mente, produto de planos e passos a serem seguidos. Daí a necessidade de métodos que explicitem esse saber incorporado/situado nas ações, e não representado na mente. O corpo (esquemas sensório-motores) ganha destaque nesta abordagem. Ele é o ponto-chave da análise da ação eficaz de trabalhadores, em contraposição à abordagem que supervaloriza as representações.

A abordagem do Curso da Ação propõe analisar os elementos que compõem a atividade - percepção, ação, situação e experiência acumulada - por meio do signo tetrádico (herdado da semiótica de Peirce) no seu desenrolar aqui e agora. $O$ uso deste recurso metodológico visa à descrição da consciência pré-reflexiva em situação, sem cair no viés cognitivista. A análise recai sobre a interação viva e situada do sujeito com o seu meio, ou seja, aquilo que o sujeito viu, percebeu, sentiu e fez em dado momento. Mais importante que apelar para os saberes ou conhecimentos refletidos ou elaborados pelo sujeito na consciência, é acessar seu saber incorporado em situação (ator engajado na prática), pois é nisto que consiste sua verdadeira expertise (Theureau, 1992). A 
abordagem do Curso da Ação permite descrever como se mesclam, na atividade, representações conscientes, ou não, da própria experiência e os elementos da situação (ações, percepções) que são significativos, aqui e agora, para o ator. O sentido resulta da composição entre elementos da experiência e da situação (incluindo o corpo) ao promover um encadeamento de signos.

Este tipo de análise permite recolocar a prática como o fator-chave da ação eficaz, o que implica, dentre outras coisas, reconhecer o corpo em atividade como lócus privilegiado da inteligência, para onde convergem processos cognitivos e ações sobre o mundo, em situações vividas e experienciadas aqui e agora. O corpo deixa de ser instrumento de execução de processos mentais e passa a ser o epicentro da inteligência prática, que se manifesta no senso de oportunidade, na preparação para a ação, na força de vontade necessária para decidir diante de situações de incerteza, na síntese entre todos os sentidos que atualizam a experiência anterior, em suma, em uma forma de inteligência que é mais eficaz praticamente, e mais econômica cognitivamente. Mais à frente, demonstraremos como o uso do corpo (percepções e gestos), associado a representações emergentes e incorporadas, é mais eficaz que o uso de representações matemáticas, determinando o que o sujeito deve fazer em cada momento do curso da sua ação de resolução de problemas práticos. Isto é contrário ao discurso hegemônico do saber científico, considerado superior ao saber prático, mas pode ser comprovado quando se analisam esses processos prático-cognitivos assumindo a primazia da prática.

\section{Método}

O método utilizado nesta pesquisa foi desenvolvido pelo Curso da Ação (Theureau, 2004) a partir da Análise da Atividade de origem francofônica, que utiliza métodos de observação e verbalização em autoconfrontação, que consiste em descrições dos trabalhadores sobre o que ele fez, como fez, para que fez e por quê, mediado por traços objetivos da atividade (Lima, 2001). Estes traços objetivos podem ser descrições de fatos observados, gravações de verbalizações entre trabaIhadores ou deles próprios em atividade, e filmagens da atividade sendo realizadas. Pretendemos, com estas verbalizações, obter o sentido implícito da ação realizada (aí incluídos a percepção, os pensamentos emergentes e as emoções) pelo próprio ator da ação, evitando julgamentos e inferências sobre a atividade do outro.
Este saber implícito e incorporado é dificilmente obtido por meio de entrevistas, que alcançam somente o saber representado e, não, o saber incorporado mobilizado em situação.

A pesquisa foi realizada numa obra predial na Região Metropolitana de Belo Horizonte/MG durante um ano e meio e em suas diferentes fases (fundação, concretagem, acabamento). A escolha das situações foi determinada pela presença de problemas envolvendo matemática e os trabalhadores escolhidos foram aqueles considerados mais eficazes na sua prática, como o encarregado, cuja atuação será analisada neste estudo. Como ele supervisionava outros trabalhadores, foi também analisada a ação de um trabalhador menos experiente e competente na atividade. Todas as situações foram filmadas e trabalhadas em verbalizações de autoconfrontação.

$A$ atividade de trabalho escolhida para ser analisada foi o assentamento de peças de cerâmica, numa tarefa de acabamento. A escolha desta situação esteve condicionada ao grau de dificuldade em resolvê-la, à existência de problemas envolvendo matemática e à presença de fracassos e sucessos em sua resolução. A comparação entre a ação eficaz e não-eficaz permitiu conhecer os determinantes da ação e dos erros, a partir do debate teórico apresentado anteriormente: a ação inteligente é determinada por representações mentais que controlam a ação (seguir um plano utilizando representações da matemática escolar) ou por habilidades incorporadas emergindo em situação? Esta pergunta será respondida mediante a apresentação do caso empírico.

\section{Atividades de resolução de problemas que envolvem a matemática no canteiro de obras}

\section{A Demanda e a Opção pela Capacitação Profissional Formal/Escolar}

A necessidade desse estudo se originou a partir da constatação de erros cometidos por trabalhadores da construção civil durante a realização de tarefas que requerem operações envolvendo a matemática. Interessados em desenvolver competências matemáticas para melhorar a performance profissional destes trabalhadores, engenheiros e empresários da construção civil ofereceram cursos profissionalizantes para o ensino da matemática escolar, pois acreditavam que a falta de tais conhecimentos matemáticos era a causa de erros, 
retrabalhos e trabalhos mal feitos. A formação profissional nos moldes escolares, o ensino da matemática escolar, se apresenta, então, como solução para melhorar o desempenho desses trabalhadores.

Essa demanda, já formulada em termos de diagnóstico e de solução que indica que os erros acontecem devido à falta de conhecimentos matemáticos - é reforçada pelo senso comum que sobrevaloriza a educação formal (conhecimentos escolares), sobretudo quando se envolve a matemática, no desenvolvimento de competências profissionais e na melhoria da performance. A concepção de desenvolvimento profissional leva a medidas internamente coerentes, mas impotentes para promover o desenvolvimento de competências práticas efetivas, como foi constatado pelos próprios engenheiros, que não obtiveram resultados práticos satisfatórios na performance dos trabalhadores após a conclusão de cursos profissionalizantes.

É neste contexto de insatisfação com as tentativas de melhorar o desempenho profissional dos operários por meio da aprendizagem matemática, que surge a necessidade deste estudo: compreender o que caracteriza a prática eficaz e não-eficaz dos trabalhadores na resolução de problemas envolvendo matemática num canteiro de obras. O encarregado e o pedreiro investigados têm diferentes níveis de formação escolar. O primeiro tem 60 anos de idade e está fora da escola há mais de 45 anos, enquanto o segundo tem 35 anos e acaba de concluir o curso profissionalizante para pedreiros oferecido pela empresa, no qual aprendeu conceitos, fórmulas e regras matemáticas escolares.

\section{Estudo de Caso: Assentamento de Cerâmica}

O caso analisado refere-se a uma atividade realizada por um encarregado de acabamento experiente e um pedreiro novato. $O$ encarregado tem mais de 30 anos de experiência na atividade de acabamento e o pedreiro 10 anos nesta função, embora possua pouca experiência em obra predial de grande porte e de alto luxo sendo, portanto, um novato nessa atividade analisada. Ambos estão envolvidos na atividade de assentar peças de cerâmica na parede acima do vão de uma janela.

A sequência em que as pedras devem ser colocadas vai da direita para a esquerda, sendo que a última pedra a ser colocada é uma tira de $4 \mathrm{~cm}$ de largura na parte superior e de $3 \mathrm{~cm}$ de largura na parte inferior (perna), resultando num dente de 90 graus entre a parte de cima e a debaixo, pelo lado direito. Esta sequência estava definida no projeto de paginação arquitetônica.
A tarefa é fazer os recortes da peça de cerâmica e seu assentamento na parede.

A peça de cerâmica analisada é a última peça a ser colocada entre a parede, que é perpendicular (à esquerda) e a carreira de cerâmicas já assentadas (à direita), como ilustra a Figura abaixo (Figura 1).
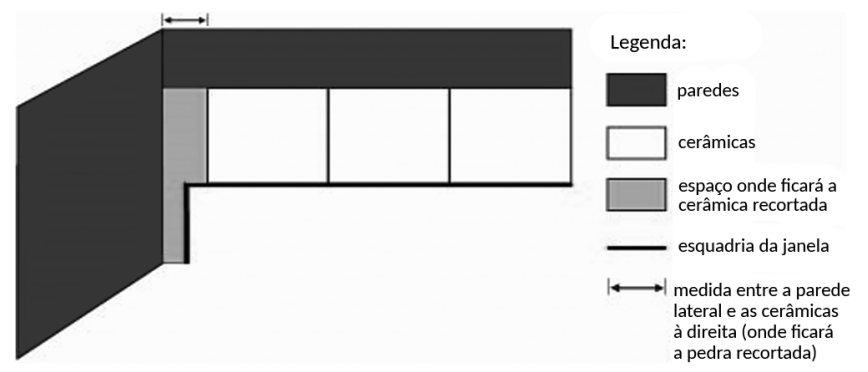

Figura 1. Vão da Janela. Fonte: Dados da pesquisa (2014).

A operação a ser feita consiste em cortar uma pedra de cerâmica que tem formato retangular, de modo a ficar como na Figura 2.

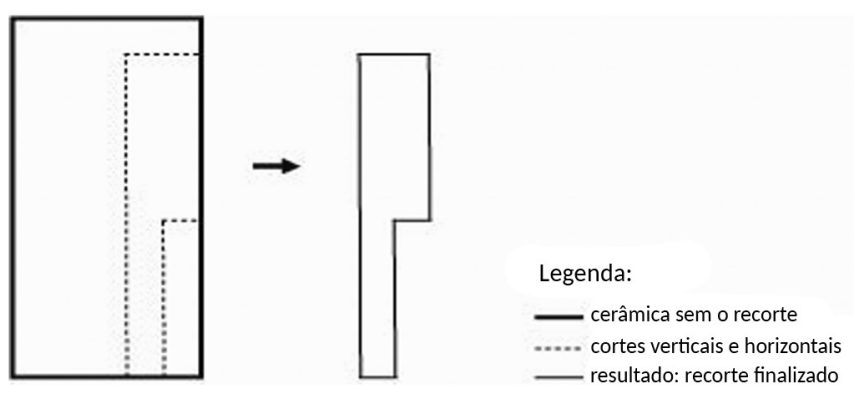

Figura 2. Representação Esquemática da Forma Final da Cerâmica Cortada e os Cortes a serem Feitos. Fonte: Dados da pesquisa (2014).

O pedreiro $(P)$ é o executor da atividade. Ele inicia sua atividade medindo, com a trena, as dimensões do local de encaixe da peça de cerâmica na parede. Primeiro, ele mede o dente entre a parte mais larga e mais fina do espaço, depois a largura do espaço mais fino (perna) e, em seguida, a altura e a largura da parte mais grossa superior. Feito isso, ele repassa estas medidas para a cerâmica com um lápis e, por fim, faz o recorte com a makita. Na hora de conferir a peça de cerâmica recortada no local, antes de assentá-la (colar com massa), P. vê que ela está com o comprimento da perna maior que o espaço na parede, sendo necessário cortá-la na base. Mas este corte não pode ser feito no pé da perna, pois se trata do lado acabado (lado original da cerâmica que não pode ter recorte, porque encontra com outra peça de cerâmica, e a regra do acabamento bem feito é sempre 
deixar o lado de fábrica nas juntas entre as cerâmicas). Assim, não teria jeito de resolver este problema, sendo necessário desprezar esta cerâmica e começar o corte em outra.

O encarregado (E), hierarquicamente superior ao pedreiro, observa sua dificuldade e intervém na atividade para ajudá-lo. Primeiro, ele mede com a trena a largura da parte superior do encaixe na parede que é mais larga $(4 \mathrm{~cm})$. Em seguida, corta a cerâmica na extremidade esquerda da peça, de modo a deixar a extremidade direita com o recorte de fábrica - lado acabado (Figura 3). Desse modo, ele obtém uma tira de $4 \mathrm{~cm}$ de largura com o recorte na esquerda, conforme a regra de acabamento.

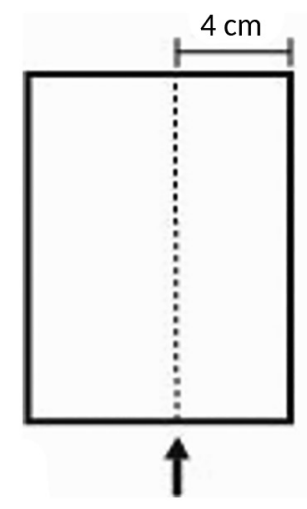

Legenda:

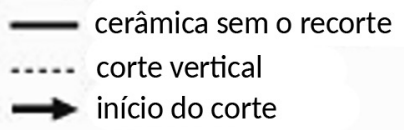

Figura 3. Primeiro Corte: Tira de $4 \mathrm{~cm}$. Fonte: Dados da pesquisa (2014).

Essa tira será usada, em seguida, como instrumento de marcação dos lados de recorte, tomando como referência o alinhamento das peças já assentadas na parede. Ele apoia a tira no espaço de encaixe e marca com um lápis os locais onde serão feitos os recortes, de acordo com o alinhamento das quinas das peças vizinhas já assentadas.

Nesta sequência, E. corta a cerâmica, seguindo estas marcações feitas na tira, e o resultado é o recorte da peça, que se encaixa perfeitamente na parede. Ao terminar a atividade, o pedreiro diz: "ufa, até que enfim conseguimos fazer!". Ao ser questionado nas entrevistas em autoconfrontação sobre esse comentário, ele explica que sua atividade exige muita atenção, muita concentração, paciência, pois ela força a mente. Segue a entrevista:

Pesquisador: o que estava acontecendo?

P: Esses cortezinhos são difíceis de fazer. O encarregado marcou mais correto, né? Eu tenho experiência, mas não é tanta. Tenho dez anos de experiência de acabamento, só que cada dia você vai aprendendo mais. feito?

Pesquisador: o que este serviço exige para ser

P: Tecnologia, tem de usar a mente, técnica. O serviço de acabamento força muito a mente da gente.

O pedreiro relata cansaço, devido à exigência do trabalho mental relacionado à técnica de fazer os recortes e a medição, ao passo que o encarregado realiza a atividade assoviando e cantando, como se fosse uma atividade leve, sem muito esforço. Ele atribui o sucesso do encarregado à sua marcação, que foi mais correta, por ter mais técnica, mais prática nesta atividade que o pedreiro. Cabe destacar que o encarregado só usou a trena para medir a primeira largura de $4 \mathrm{~cm}$ e fazer a tira, não utilizando mais este instrumento de medição para as outras medidas. A técnica permitiu a marcação pelo alinhamento das cerâmicas, ponto-chave de sua eficácia? Analisaremos, a seguir, os determinantes dos erros e acertos de ambos e como a atividade mental forçada e a atividade corporal emergente foram decisivas para o fracasso e o sucesso do pedreiro e do encarregado, respectivamente.

\section{Análise da Ação na Resolução do Problema Prático}

Na sua primeira sequência de recorte, o pedreiro faz quatro medições com a trena (as medidas da altura da perna da peça, a largura da parte mais grossa, da parte mais fina e as dimensões do dente), mas se esquece de medir a altura total do espaço do encaixe, feita somente depois de o erro ser percebido. Esta medida é importante, porque o local de encaixe é menor que a altura da peça de cerâmica original, sendo necessário cortá-la para o encaixe perfeito. Mas ele não pode cortá-la em qualquer lugar, é preciso respeitar a regra do lado acabado que, no caso, deve ser no topo da peça e, não, no pé. Como ele se esqueceu dessa medida, a perna ficou comprida demais, implicando o descarte e o recomeço da sequência numa nova peça de cerâmica. "Às vezes, um momento de esquecimento, igual eu te falei, o serviço é paciência. Se não tiver muita paciência, você acaba fazendo errado" (Pedreiro). Ele diz que se esqueceu, porque estava preocupado com o recorte do dente, considerado mais difícil: "Esses cortezinhos são difíceis de fazer" (Pedreiro). Ele prefere então começar sua sequência de medição por esta medida, já que ela é crucial para o sucesso ou o fracasso do encaixe da peça. "Eu faço o recorte mais difícil primeiro, para garantir a pedra. Um erro nestes recortes faz perder a pedra, faço primeiro o 
mais crítico para depois fazer o mais fácil. A preocupação é não errar, é você medir certo" (Pedreiro). O que é medir certo? Medir certo implica várias exigências: i) medir com precisão, inclusive os milímetros (quando é feito com a trena); ii) medir todas as dimensões para o encaixe perfeito, e iii) respeitar os lados acabados. Ou seja, não basta medir com precisão, é preciso saber o que medir e como medir (para atender à exigência do lado acabado) - o que pode tornar a atividade complexa, dependendo do número de medidas a obter e das condições de medição. Neste caso específico, a janela era muito alta. Ele estava em cima de um andaime e usava a trena com dificuldade no espaço estreito para seu corpo. Ele colocava a trena no espaço do encaixe e decorava as medidas em milímetros, que seriam, em seguida, passadas para a peça de cerâmica, para ser cortada. As medidas a ser memorizadas eram várias, e ele ainda tinha de ficar atento às dimensões e à regra presente no lado acabado. Todas essas exigências tornavam sua atividade mentalmente cansativa.

O encarregado adota estratégias diferentes do pedreiro: primeiro faz a tira, que é um recorte, aplicando a regra do lado acabado nas laterais; em seguida, coloca a tira na parede, posicionando-a de modo a garantir o lado acabado no pé (base da peça encostada na cabeça da pedra assentada) e a usa como instrumento para marcar as demais medidas pelo alinhamento das pedras já assentadas. Essa estratégia possibilita ver a marcação pelo alinhamento das pedras assentadas nas carreiras ao lado e embaixo, sem precisar forçar sua mente para se lembrar do que medir, das medidas feitas e dos lados acabados. Ele adota uma estratégia de medição não escolar (desenvolvida na sua prática de pedreiro), quando faz a tira e marca pelo alinhamento. Com isso, ele cria uma estratégia que une medição e marcação na cerâmica numa única ação: marcação na própria tira na qual serão feitos os recortes. Trata-se de uma estratégica eficaz e econômica, pois, ao criar a tira e posicioná-la corretamente na parede (respeitando a regra do lado acabado no pé), ele facilita sua atividade, eliminando a etapa de medição com a trena das dimensões do desenho da peça. O encarregado diz que sempre que pode fazer a tira e marcar pelo alinhamento ele o faz, pois isso facilita sua atividade, torna-a mais rápida e precisa, uma vez que não é necessário memorizar as medidas com milímetros, evita o risco de esquecimento e de erro no uso da trena, o que pode aumentar ou diminuir alguns milímetros à medida. Assim, ele desenvolve uma técnica de medição muito mais eficaz que aquela do pedreiro, exatamente pelo fato de tornar sua atividade menos pesada, cognitivamente. Basta olhar para a tira posicionada na parede com os lados acabados (regra do lado acabado implícito no gesto) para saber o lugar de marcar, deixando suas habilidades incorporadas de ver e marcar emergirem, sem precisar fazer nenhum esforço consciente para refletir e planejar todas as dimensões a serem medidas.

As habilidades de ver e marcar corretamente não são naturais. O pedreiro, quando executava a sequência ditada pelo encarregado, viu e marcou um alinhamento de forma incorreta. Segundo ele, foi golpe de vista (como uma ilusão de ótica) que o fez ver a linha em um lugar errado devido à sua posição no andaime. $O$ encarregado experiente logo percebeu o erro e o corrigiu, informando ao pedreiro como deveria posicionar seu corpo e seu olhar para fazer a marcação correta. Isto mostra que é preciso educar o corpo para ele ver e marcar corretamente. Não se trata de uma habilidade natural, mas adquirida e treinada, na prática.

O esforço cognitivo do pedreiro é maior que o empreendido pelo encarregado, pois ele precisa forçar sua mente para planejar cada passo da medição a fim de não se esquecer das dimensões a medir, da regra do lado acabado e das medidas. Por isso, o pedreiro credita o sucesso da tarefa ao controle consciente de cada passo a ser realizado. Mas sua prática demonstrou o contrário: quanto maior o esforço cognitivo de ter de pensar em todas as exigências durante a realização da atividade, maiores as chances de erro, pois o problema fica mais pesado cognitivamente, aumentando o risco de esquecimentos. Forçar a mente, nesse caso, não é sinônimo de eficácia.

O ponto-chave do sucesso e do fracasso, então, não é o esforço mental que cada um despende para agir, como acredita o pedreiro, mas, sim, a ação que prescinde desse esforço. Parafraseando Ingold (2010): "o que diferencia o especialista do relativamente iniciante não é a complexidade ou a escala de elaboração de seus planos ou representações, mas até onde ele pode prescindir disso" (p.18). A eficácia prática é, portanto, antes, um processo prático de ações, percepções e representações em situação que uma estrutura complexa da mente que segue planos - o que comprova a tese da ação situada em contraposição à tese cognitivista na ação eficaz.

O encarregado criou condições de fazer a medição pela tira em vez da trena, o que tornou sua atividade muito mais emergente e corporal, enquanto a atividade do pedreiro guiada pelo planejamento consciente do quê medir, como medir e onde medir, seguindo a 
sequência clássica escolar de medição pela trena, depois marcação e recorte, tornou sua tarefa mais pesada cognitivamente e também mais sujeita a erros. A tese da ação eficaz determinada pelas habilidades incorporadas desenvolvidas na prática e emergentes na situação aqui e agora se comprova nesse caso, ao mesmo tempo em que confirma a ineficácia de atividades com sobrecarga cognitiva. Quanto maior o esforço mental para agir em determinadas situações práticas, menos eficaz se é, como demonstram também alguns estudos de Bisseret (1995); Dekker (2002); Dreyfus \& Dreyfus (1986).

\section{Plano, ação situada, conceitos matemáticos e o curso da ação}

Foi possível constatar, a partir do caso analisado, como se dá a inteligência, na prática. A eficácia prática do encarregado na resolução do problema dependeu mais das habilidades incorporadas mobilizadas em situação, como as operações realizadas (tira, marcação pelo alinhamento), o momento em que aconteceram, as condições criadas para facilitar a percepção e a ação, o uso do corpo para ver e marcar, que do próprio domínio de um plano formal de medição, marcação e recorte, usando instrumentos escolares como a trena, tipicamente ensinado nos cursos profissionalizantes. Contrariamente ao que pensavam os engenheiros, o curso profissionalizante, mediante o ensino de representações matemáticas, não foi suficiente para produzir ação eficaz, ao passo que as habilidades incorporadas desenvolvidas na prática mostraram ser cruciais na resolução satisfatória do problema envolvendo matemática.

Alguns estudiosos corroboram com os nossos resultados: Lave (1996), na pesquisa realizada com participantes do programa Vigilantes do Peso, mostra que as pessoas desenvolvem estratégias de medição diferentes dos procedimentos escolares, como medir o tamanho do bife comparando-o ao tamanho da mão, a quantidade de leite pelo espaço que ocupa no copo, abandonando progressivamente as estratégias escolares de medição, como o uso de balança, a medida com régua, para ganhar em eficácia e agilidade. A tira criada pelo encarregado é também uma invenção que transforma o objeto de trabalho em instrumento de medição, de modo mais eficaz que a trena. Os experts da prática geralmente criam instrumentos e recursos diferentes dos escolares para facilitar seu trabalho e aumentar sua eficácia, ao contrário do que comumente pensam os engenheiros, que os estigmatizam como gambiarras.
Os estudos sobre ocorrência de acidentes (Clot, 1999; Dekker, 2002), e procedimentos de segurança de voo (Bisseret, 1995) também demonstram como a transferência da inteligência para o corpo é a forma mais eficaz para lidar com os imprevistos e os riscos do processo, diminuindo os cálculos mentais e a manipulação de representações, ao mesmo tempo em que se aumentam as estratégias corporais de controle da situação. Os controladores de voo (Bisseret, 1995) mais eficazes na segurança do espaço aéreo são aqueles que conseguem se guiar pelo controle perceptual das imagens dos aviões no radar, ao passo que aqueles que realizam cálculos matemáticos baseados em algoritmos são mais precisos nas suas estimativas, porém menos prudentes na segurança, uma vez que a exigência cognitiva requerida nos cálculos matemáticos não Ihes permite gerir, concomitantemente, outras variáveis. Os experientes que se guiam por radar afirmam que o verdadeiro ganho na mudança da estratégia mental de cálculo para o controle perceptual por meio do radar é a possibilidade de antecipar e administrar situações, ao mesmo tempo em que controla os aviões pelo radar. Este é um exemplo de como a transferência de habilidades cognitivas para o corpo pode tornar a ação mais eficaz e segura.

Esses resultados também corroboram os estudos de Dreyfus e Dreyfus (1986) sobre os níveis de desenvolvimento de competências, sendo o mais elevado, o nível expert, aquele em que as habilidades incorporadas estão tão desenvolvidas que não é mais preciso pensar para fazer, mas simplesmente fazer, mobilizando todo o saber incorporado emergente na situação. Assim, transformar atividades cognitivas em habilidades corporais, ao contrário do que pensam os cognitivistas, é aumentar a eficácia.

\section{Conclusão: O que muda na formação profissional}

A formação profissional, nos moldes tradicionais ou da Didática Profissional (Pastré, 2011), se baseia na separação entre a transmissão de representações na escola e a prática. Esta formação herdada do modelo escolar prioriza a transmissão verbal de conhecimentos do professor para os alunos, como conceitos, procedimentos, técnicas e outras informações sobre a atividade. Esse é o momento-chave da aprendizagem, sendo a prática apenas uma etapa secundária de aplicação desses conhecimentos, de modo a consolidar a aprendizagem. A concepção por trás desse modelo indica que 
a mente determina a ação, já que a prática nada mais é que a aplicação da teoria. Neste caso, aprender no curso profissionalizante a utilização de determinados conhecimentos, medidas em milímetros e centímetros, uso da trena, a sequência de medição, marcação e controle, entre outros, seria um pré-requisito essencial do sucesso, sem muita preocupação com a educação do corpo. Este foi o modelo aprendido pelo pedreiro no curso profissionalizante.

A segunda opção é colocar a prática como o momento-chave da ação eficaz. É o engajamento prático numa determinada atividade que produz a ação eficaz, como a educação do corpo e dos sentidos (Ingold, 2010), isto é, a aprendizagem de uma nova técnica como a tira posicionada, de modo a atender às exigências do lado acabado, além de aprender a posicionar o corpo para ver e marcar.

Para esclarecer nossa posição, considerem-se as duas situações aqui colocadas sobre a aprendizagem: na concepção tradicional da formação profissional, o recomendado é o ensino dos métodos escolares e da sequência lógica de medição (uso da trena), marcação e recorte. Já foi demonstrado que essa prática é menos eficaz pelos motivos mencionados (sobrecarga cognitiva, esquecimento). A segunda possibilidade, mais eficaz do ponto de vista cognitivo e prático, seria educar o corpo do trabalhador. Ensinar-lhe, na prática, o corte da tira e o modo de posicioná-la corretamente na parede, considerando o lado acabado. Associar essa ação ao modo de posicionar o corpo e a mão para ver (percepção) e marcar (gesto) corretamente é combinar ação, percepção e cognição numa dinâmica mais leve cognitivamente e menos sujeita a erros. Engajá-lo na atividade prática não é criar ou melhorar o plano a ser seguido conscientemente, mas, sim, desenvolver novas habilidades incorporadas de ver e fazer, tornando assim a atividade mais espontânea e emergente.

A formação profissional mudaria, assim, seu propósito de transmissora de representações (escolares ou práticas) para o de desenvolvedora de habilidades incorporadas do sujeito na prática. Aprender práticas eficazes que incorporem regras do métier parece ser o modelo mais eficaz para o desenvolvimento de competências práticas. Os cursos profissionalizantes deveriam, então, abordar o estudo das situações práticas de aprendizagem e procurar desenvolver uma engenharia de situações de aprendizagem, como, por exemplo: quando e como possibilitar essas aprendizagens; como criar momentos de aprendizagem no antigo modelo mestre/aprendiz (Lave
\& Wenger, 1991); oferecer programas de mentoring, acompanhamento e resolução de situações-problema; promover correção e feedback; apresentar a identificação de decisões críticas e pontos de atenção, etc. Quando mais situações estruturadas de aprendizagem na prática tiver uma organização, mais eficientes serão os trabalhadores envolvidos. O programa on the job training (Frazis \& Loewenstein, 2007) parte da premissa de que é necessário aprender fazendo, mas faltam-lhe os conceitos e instrumentos operacionais que a Teoria do Curso da Ação e da Ação Situada pode oferecer, por meio de uma engenharia de situações de aprendizagem.

\section{Referências}

Acioly-Régnier, N. M. (1995). A justa medida: um estudo sobre competências matemáticas de trabalhadores da cana de açúcar no domínio da medida. In A. Schliemann, D. Carraher, A. Spinillo, L. Meira, \& J. Falcão (Orgs.), Estudos em Psicologia da educação matemática (pp. 108-137). Recife: Editora Universitária da UFPE.

Bishop, A. J. (1988). Mathematical enculturation: a cultural perspective on mathematics education. Dordrecht, Holanda: Kluwer Academic Publishers.

Bisseret, A. (1995). Representation et decision experte: psychologie cognitive de la decision chez les aiguilleurs du ciel. Toulouse: Octares Editions.

Carraher, T.; Carraher, D., \& Schliemann, A. (1988). Na vida dez, na escola zero. São Paulo: Cortez.

Clot, Y. (1999). La fonction psychologique du travail, Paris: PUF.

Da Rocha Falcão, J.T. (1996). Proposição de seqüências didáticas para o ensino de conceitos matemáticos: $O$ caso da álgebra elementar. In: M. H. Novaes \& M. R. F. Britto (Orgs.), Psicologia na educação: articulação entre pesquisa, formação e prática pedagógica, pp. 135-150. Rio de Janeiro: Associação Nacional de Pesquisa e PósGraduação em Psicologia.

Da Rocha Falcão, J. T. (2006). O que sabem os que não sabem? Contribuições para a exploração psicológica das competências cognitivas humanas. In. L. Meira \& A. Spinillo (Orgs.), Psicologia cognitiva: cultura, desenvolvimento e aprendizagem (pp. 13-45). Recife: Editora Universitária da UFPE.

Dekker, S. (2002). The field guide to human error investigations. Inglaterra: Ashgate Publishing Ltd.

Dreyfus, H., \& Dreyfus, S. (1986). Mind over machine: the power of human intuition and expertise in the era of the computer. Nova lorque: The Free Press.

Duarte, C. G. (2002). Etnomatemática, currículo e práticas sociais do mundo da construção civil (Dissertação de Mestrado). Recuperado de http://www.portalanpedsul.com.br/admin/uploads/2004/painel/ painel/09_50_49_etnomatematica,_curriculo_e_praticas_sociais_ do_\%20mundo_da_co.pdf

Frazis, H., \& Loewenstein, M. A. (2007). On-the-job training. Hanover: Now Publishers Inc.

Gatewood, J. B. (1985). Actions speak louder than words. In J. W. D. Dougherty (Org.), Directions in cognitive anthropology (pp. 199-219). Urbana e Chicago, EUA: University of Illinois Press. 
Ingold, T. (2010). The perception of the environment: essays on livelihood, dwelling and skill. Londres: Routledge.

Knijnik, G.; Wanderer, F., Giongo, I. M., \& Duarte, C. G. (2012) Etnomatemática em movimento. Belo Horizonte: Autêntica.

Lave, J. (1988). Cognition in practice. Cambridge: University Press Cambridge.

Lave, J. (1996). A selvageria da mente domesticada. Revista Crítica de Ciências Sociais, (46), 109-134. Recuperado de http://www.ces. uc.pt/rccs/index.php?id=597\&id_lingua $=1$

Lave, J. (2011). Apprenticeship in critical ethnographic practice. Chicago: University Chicago Press

Lave, J., \& Wenger, E. (1991). Situated learning: legitimate peripheral participation. Cambridge: University Press.

Lima, F. (1995). Les contraintes au travail et la dimension éthique de l'activité (Tese de Doutorado). Recuperado de http://www.theses. $\mathrm{fr} / 1995 \mathrm{CNAM0229}$

Lima, F. (2001). A formação em Ergonomia: reflexões sobre algumas experiências de ensino da metodologia de análise ergonômica do trabalho. In C. Kiefferk, I. Fagá, \& M. R. Sampaio (Orgs.), Trabalho, educação e saúde: um mosaico em múltiplos tons, pp; 133-148. Vitória: Fundacentro.

Merleau-Ponty, M. (1945). Phénomenologie de la perception. Paris: Gallimard.
Merleau-Ponty, M. (1968). The intertwining-the chiasm. The visible and the invisible (A. Linguis, Trad., pp. 130-155). Evanston, IL: Northwestern University Press.

Pastré, P.(2011).La didactique professionnelle. Approche anthropologique du développement chez les adultes. Paris: PUF.

Suchman, L. (1987). Plans and situated actions: the problem of human/ machine communication. Nova lorque: Cambridge University Press.

Suchman, L. (2007). Human-machine reconfigurations. Nova Iorque: Cambridge University Press.

Theureau, J. (1992). Le cours d'action: méthode élémentaire. Toulouse: Octarès.

Theureau, J. (2004). L'hypothèse de lacognition (ou action) située et latradition d'analysedutravail de l'ergonomie de langue française. @ ctivités, 1(2), 11-25. Recuperado de https://activites.revues.org/1219

Varela, F.; Thompson, E., \& Rosch, E. (1991). The embodied mind: cognitive science and human experience. Cambridge: MIT Press.

Vera, A. H. (2003). By the seat of our pants: the evolution of research on cognition and ac- tion. The Journal of the Learning Sciences, 12 , 275-280. doi: 10.1207/S15327809JLS1202_8

Vera, A. H., \& Simon, H. (1993). Situated action: a symbolic interpretation. Cognitive Science, 17(1), 7-48. doi:10.1207/s15516709cog1701_2

Vergnaud, G. (1996). Au fond de l'action, la conceptualisation. In J. M. Barbier (Org.), Savoirs théoriques et savoirs d'action (pp. 275-292). Paris: Presses Universitaires de France.

Renata Bastos Ferreira Antipoff, Doutora em Educação pela Faculdade de Educação da Universidade Federal de Minas Gerais (FAE/UFMG), é Professora do Instituto Federal de Minas Gerais campus Ouro Preto (IFMG/OP). Endereço para correspondência: Rua Pio Porto de Menezes, 120, apto. $1102^{\text {a }}$ Luxemburgo, Belo Horizonte - MG, CEP: 30380-300. Telefones: (31) $33091904 \mathrm{e}$ (31) 998991904. E-mail: renata.bastosfe@yahoo.com.br

Cristina de Castro Frade, Doutora em Educação pela Faculdade de Educação da Universidade Federal de Minas Gerais (FAE/UFMG), Pós-Doutorado na London South Bank University, Londres, Educação Matemática, é Professora da Faculdade de Educação da Universidade Federal de Minas Gerais (FAE/UFMG). E-mail: frade.cristina@gmail.com 